\title{
Propiconazole Distribution and Effects on Ceratocystis fagacearum Survival in Roots of Treated Red Oaks
}

\author{
Ryan A. Blaedow, Jennifer Juzwik, and Brian Barber
}

First author: North Carolina Division of Forest Resources, 762 Claridge Nursery Road, Goldsboro 27530-7965; second author: United States Department of Agriculture-Forest Service, Biological and Environmental Influences on Forest Health and Productivity Research Unit, St. Paul, MN 55108; and third author: Water Resources Center, University of Minnesota, St. Paul 55108. Accepted for publication 15 May 2010.

\begin{abstract}
Blaedow, R. A., Juzwik, J., and Barber, B. 2010. Propiconazole distribution and effects on Ceratocystis fagacearum survival in roots of treated red oaks. Phytopathology 100:979-985.

We investigated the interaction between the oak wilt pathogen (Ceratocystis fagacearum) and propiconazole in lower stems and roots of Quercus rubra to better understand published reports of fungicide failure after 2 years. Propiconazole was infused into mature oaks in July 2004 and roots were inoculated with pathogen endoconidia $1.0 \mathrm{~m}$ from injection sites at \pm 2 weeks of fungicide treatment. Pathogen presence in

was detected in the roots ( $\leq 1.0 \mathrm{~m}$ from injection sites) of all treated trees at 2, 12, and 24 months. Propiconazole was detected in all samples $(\mathrm{n}=$ $68)$ at 2 and 12 months and in $93 \%$ of samples $(n=72)$ at 24 months with concentrations ranging from $815 \mathrm{ppm}$ (12 months in lower stem) to $0.7 \mathrm{ppm}$ (24 months in most distal root segment). Although pathogen isolation incidence was lower in treated than disease control trees at 2 and 12 months, at no time did an infused oak fail to yield the fungus upon isolation. The results document basipetal movement and degradation of propiconazole, as well as the survival of the pathogen, over time in roots and lower stems of infused red oaks.
\end{abstract} wood samples was determined by isolation and fungicide concentrations measured using gas chromatography-mass spectrometry. Propiconazole
Additional keywords: Alamo, chemical control, wilt disease.
Oak wilt, caused by the vascular pathogen Ceratocystis fagacearum, is an important disease of oaks (Quercus spp.) in the eastern United States (20). Its ability to kill red oaks (Section Lobatae) several weeks after onset of incipient wilt makes $C$. fagacearum one of the most destructive forest pathogens known $(10,20,24)$. Over 33 species of oaks are known to be susceptible to C. fagacearum, although white oaks (Section Quercus) exhibit varying degrees of resistance (20). The disease is particularly devastating for reds oaks, such as northern red oak (Q. rubra), black oak ( $Q$. velutina), and northern pin oak ( $Q$. ellipsoidalis) in the Great Lakes region; and for live oaks ( $Q$. fusiformis and $Q$. virginiana) in Texas.

Disease centers are initiated when overland transmission of the pathogen occurs via insect vectors such as sap beetles of the family Nitidulidae and oak bark beetles (Pseudopityopthorus spp.) (10). Expansion of disease centers occurs when C. fagacearum spreads through common root systems of clonally propagated live oaks or root grafts between proximal oaks $(4,10)$. Below-ground spread of the pathogen is managed using mechanical root disruption (e.g., vibratory plow) or with systemic fungicides $(4,11)$.

Propiconazole (1-[(2-(2,4-dichlorophenyl)-4-propyl-1,3-dioxolan-2-2-yl) methyl]-1H-1,2,4-triazole) is a systemic fungicide applied via intravascular injection at the root crown or lower stem that was first used in the 1980s to prevent losses of live oaks from root transmission of the oak wilt pathogen (2). In the Great Lakes region, propiconazole is widely used for preventive treatment of red oaks within root-grafting distance of diseased trees or on sites

Corresponding author: J. Juzwik; E-mail address: jjuzwik@fs.fed.us

doi:10.1094/PHYTO-01-10-0008

This article is in the public domain and not copyrightable. It may be freely reprinted with customary crediting of the source. The American Phytopathological Society, 2010 where mechanical root disruption cannot be conducted. Published reports suggest that a single treatment with propiconazole is highly effective in preventing oak wilt development in red oaks growing within root grafting distance of diseased oaks for no longer than 2 years or two growing seasons after treatment in Minnesota and Texas $(5,9,15,23)$ or up to 3 years in Michigan (16).

The putative cause of treatment failure after two or more years has been attributed to degradation of propiconazole over time. Osterbauer and French (15) were able to detect propiconazole in the stem and branches of propiconazole-treated red oaks 12 months, but not 20 months after injection using a thin-layer chromatography assay. Armstrong (6) detected the fungicide in the crown of American elms (Ulmus americana) treated with propiconazole for Dutch elm disease control, 7 months after treatment, but not after 12 months using gas chromatographymass spectrometry (GCMS). In the same study, Armstrong (6) determined that propiconazole degradation is temperature dependent and the half-life of propiconazole at $25^{\circ} \mathrm{C}$ was between 67 to 101 days. The absence of detectable levels of propiconazole in the stem or branches after 1 year suggests that trees could be vulnerable to infection after that time. C. fagacearum is capable of surviving in roots of wilted oaks for 5 years or more $(18,23)$; thus, root disruption and/or retreatment with propiconazole is likely necessary for continued disease protection.

Early observations of treatment efficacy led Appel (3) to suggest that propiconazole injections do not prevent the spread of $C$. fagacearum through the root system or across root grafts. Theoretically, uniform distribution of the chemical in the vascular system of both above- and below-ground tissues of treated oaks is needed to prevent colonization. While acropetal translocation of propiconazole in the transpiration stream is believed to prevent invasion and colonization of above-ground tissues, it does not appear to provide a barrier to root transmission of the pathogen. 
Basipetal movement of propiconazole from the injection site has not been demonstrated in red oaks. However, the fungicide has been detected in the primary roots of live oak (D. N. Appel, personal communication) and peach (Prunus sp.) (1) less than $0.5 \mathrm{~m}$ from the point of injection following preventive treatment for oak wilt and Armillaria root disease, respectively. Basipetal movement of propiconazole in trees could possibly occur via symplastic translocation through the phloem into the roots; however, triazole compounds in general have little, if any, phloem mobility (14). Downward movement of xylem-mobile dyes following nonpressurized root flare injection has been demonstrated recently for red oaks (21). Based on these results, Tattar (21) speculated that downward movement of propiconazole following injection at the root flare zone may explain multiyear disease control of C. fagacearum.

The concentration of propiconazole required to kill the oak wilt pathogen in oak tissues is not known. When tested against several Texas isolates of $C$. fagacearum in vitro, propiconazole was fungistatic at 10 to $100 \mathrm{ppb}$ and fungicidal at 400 to $600 \mathrm{ppb}$ (22). Currently, there is no evidence to suggest that propiconazole is translocated into roots in quantities that would exert fungicidal activity against $C$. fagacearum. Because disease development does not occur until the oak wilt pathogen invades above-ground tissues $(18,19,25)$, root-graft transmission that occurs in oaks prior to or after treatment with propiconazole may result in latent infections of the root system. Presence of $C$. fagacearum in the roots of treated oaks could subsequently permit disease development after the fungicide degrades in above-ground tissues over time. The observations of oaks wilting two or more years after treatment would be consistent with such a scenario.

The objectives of this study were to determine if propiconazole movement into primary roots occurs following macroinjection at the root flare and to determine if $C$. fagacearum can infect, survive, and spread through the root system of treated trees. Characterization of the host-pathogen fungicide interaction over time could improve our understanding of observed prophylactic effects of propiconazole application and the reasons for treatment failure after two or more years.

\section{MATERIALS AND METHODS}

Experimental design. Four spatially separated experimental plots, each consisting of six randomly selected mature northern red oaks, were established in a fragmented red oak forest in Anoka County, Minnesota. Oak wilt was not observed in any of the selected forest fragments. All six trees within a plot received the same treatment combination of fungicide and/or pathogen to prevent possible transmission of the pathogen or translocation of fungicide across root grafts from trees assigned to different treatment combinations. The sizes of the study trees ranged from 16.7 to $42.7 \mathrm{~cm}$ diameter at $1.4 \mathrm{~m}$ height (dbh). Treatment combinations included (i) prophylactic treatment: a single macro-infusion application of propiconazole applied 2 weeks prior to root inoculation with $C$. fagacearum; (ii) therapeutic treatment: a single macro-infusion application of propiconazole applied 2 weeks after root inoculation with C. fagacearum; (iii) fungicide control: a single macro-infusion application of propiconazole, simulated root inoculation with sterilized distilled water; and (iv) disease control: single macroinfusion application of water, root inoculation with C. fagacearum.

Treatment application. Propiconazole (Syngenta Crop Protection Inc., Greensboro, NC), formulated as the suspension concentrate Alamo (14.3\% active ingredient), was applied to northern red oaks in July 2004 using a standard macro-infusion technique consisting of $20.0 \mathrm{ml}$ of the fungicide suspended in 1.0 liter of water per $2.5 \mathrm{~cm}$ of stem diameter at $1.4 \mathrm{~m}$ height, applied under pressure (138 to $276 \mathrm{kPa}$ ) as described by Amiri et al. (1). Injection tees, connected to a pressurized chemical tank via a network of plastic tubing, were placed into the root flares just below the root collar. Tees were inserted into the outermost ring of xylem through a $0.95 \mathrm{~cm}$ hole created with a high-helix drill bit. Tees were spaced so as to utilize approximately 1 tee per $1.7 \mathrm{~cm} \mathrm{dbh}$ around the circumference of the tree.

Trees were inoculated with $C$. fagacearum through three primary roots per tree, $1.0 \mathrm{~m}$ from the root collar to simulate root graft transmission of the pathogen. An air excavation tool (Airspade, Guardair Corp., Chicopee, MA) was used to displace mineral soil and expose roots to be inoculated. Each of the three inoculations were performed by drilling a $0.64-\mathrm{cm}$-diameter hole with a high-helix drill bit $2.0 \mathrm{~cm}$ deep into the root, and then applying $1.0 \mathrm{ml}$ of a conidial suspension $\left(10^{6}\right.$ conidia $\mathrm{ml}^{-1}$ in sterilized distilled water) through a $5.0-\mathrm{ml}$ pipette tip held in place in the hole using moldable epoxy putty. Following complete uptake of the conidial suspension, the holes were sealed with putty, wrapped with laboratory film, and exposed roots were covered with sand to the original soil grade.

Assays. Following propiconazole application (2, 12, and 24 months), the root systems of two trees from each treatment/plot were reexcavated. For each of the three inoculated primary roots from each tree, the segment of root between the propiconazole injection site and inoculation site was removed and placed in cold storage $\left(4^{\circ} \mathrm{C}\right)$. Each collected root was subsampled $(8.0 \mathrm{~cm}$ long root segments) at $33 \mathrm{~cm}$ intervals. In addition, three wood samples were taken from the stem of each tree $33 \mathrm{~cm}$ above the injection point, from the same vascular columns as each sampled root. Root subsamples and stem wedges were split radially; one-half of the subsample was assayed for the presence of $C$. fagacearum and the other assayed for propiconazole.

Root and stem samples were assayed for $C$. fagacearum using a standard isolation protocol (17). Following a period of 2 to 3 weeks of refrigerated storage, samples were surface-sterilized with $95 \%$ ethanol and briefly flamed. Twelve small wood chips $(\approx 0.5 \mathrm{~cm}$ long) were removed from outer rings of xylem along the length of the root segment with a sterilized wood gouge. Wood chips were plated onto $10 \%$ lactic acid-amended potato dextrose agar (Difco Laboratories, Becton, Dickinson, and Co., Sparks, MD) and incubated in the dark at $25^{\circ} \mathrm{C}$ for 30 days. Presence of C. fagacearum was monitored weekly on plates; a second attempt to isolate the pathogen was made from any root or stem samples which did not yield the pathogen from the first attempt. Colony appearance and endoconidia characteristics were used to identify C. fagacearum (7).

The concentration of propiconazole in root and stem samples was determined using a modified microwave-assisted extraction procedure (6) and GCMS. The concentration in each root or stem sample was individually determined twice to demonstrate repeatability. Samples were rinsed to remove mineral soil, chopped into small cubes (approximately $1.0 \mathrm{~cm}^{3}$ ), frozen, coarsely ground using a Model 4 Wiley Mill (Thomas Scientific, Swedesboro, New Jersey) to a size of less than $2.0 \mathrm{~mm}$, and then dried at room temperature. For extraction, $5.0 \mathrm{~g}$ of dried wood was placed in a $85 \mathrm{~mm}$ polystyrene petri dish, saturated with $30.0 \mathrm{ml}$ of methanol (99.9\% purity), and covered. Extractions were conducted in a Pelco 3441 Laboratory Microwave System (Ted Pella Inc., Redding, CA) fitted with a Pelco 3430 Microwave Power Controller, a Pelco ColdSpot water-cooled stage cooled by an external chiller unit (Forma Scientific Bath and Circulator Model 2945, Forma Scientific Inc., Marietta, OH), and a thermocouple temperature probe. Up to nine samples could be processed per extraction; operating conditions were $100 \mathrm{~W}$ for 15 min with the water-cooled stage set to $14^{\circ} \mathrm{C}$. The water-cooled stage was used to keep sample temperature below the boiling point of methanol, and to provide a water load for microwave absorption which maintains an evenly distributed microwave flux up to $8.0 \mathrm{~cm}$ above the stage area for uniform processing.

Following extraction, samples were filtered through a fiberglass filter in a polypropylene funnel, and the solvent collected in 
$15-\mathrm{mm}$ borosilicate glass vials. The filtrate was evaporated to dryness using nitrogen blowdown, rediluted in a 5:1:1 hexane/acetone/methanol mixture, and the supernatant removed and evaporated again using nitrogen blowdown. Samples were resuspended in $1.5 \mathrm{ml}$ of methanol and centrifuged at high speed for $10 \mathrm{~min}$, and $1.0 \mathrm{ml}$ of the supernatant was transferred to gas chromatography vials for analysis.

Analysis was performed with a HP6890N Gas Chromatography System with MSD (mass selective detector) (Agilent Technologies, Wilmington, DE) operating in SIM (select ion monitoring) mode. Operating conditions were as follows: the initial oven temperature was $180^{\circ} \mathrm{C}$ with a temperature ramp of $15^{\circ} \mathrm{C} / \mathrm{min}$ to $300^{\circ} \mathrm{C}$ and held for $10 \mathrm{~min}$. A $2.0-\mu$ injection in splitless mode with an approximate flow rate of $54 \mathrm{ml} / \mathrm{min}$ onto a HP-5MS 5\% Phenyl Methyl Siloxane $30 \mathrm{~m}$ capillary column (Agilent Technologies) was used for chemical separation. Ions monitored in SIM were 173, 175, 191, and $259 \mathrm{~m} / \mathrm{z}$.

Peak area values of propiconazole concentrations were obtained from the chromatogram for each sample. Propiconazole concentrations $(\mu \mathrm{g} / \mathrm{ml})$ in analyzed extracts was calculated by the external calibration method. Calibration curves were constructed by triplicate analysis of at least three standards made by serial dilution of a stock solution of propiconazole (Tilt, 97.2\% purity, Chemical Services Inc., West Chester, PA) dissolved in methanol (99.9\% purity); correlation coefficients for calibration curves were $r>0.99$. Calibration curves were constructed for every 10 to 15 tissue samples analyzed.

Propiconazole concentrations $(\mu \mathrm{g} / \mathrm{g})$ in root and stem samples were then calculated by dividing propiconazole concentration in analyzed extracts by the average percent recovery, which was calculated from analysis of wood samples spiked with propiconazole. Spiked samples consisted of $5 \mathrm{~g}$ of milled and dried root tissue from nontreated northern red oak. Samples were spiked with $1.0 \mathrm{ml}$ aliquots of $150,100,50,25,10,5$, and $1 \mathrm{ppm}$ dilutions of propiconazole prepared from a stock solution of analytical grade propiconazole (Tilt, 97.2\% purity, Chemical Service Inc.) dissolved in methanol (99.9\% purity). For each concentration, three samples were spiked and the test replicated six times. Standard solutions were added slowly to cover the surface of the wood matrix. The solvent was allowed to evaporate, and the spiked wood matrix was allowed to equilibrate for $36 \mathrm{~h}$ in darkness. Spiked samples were analyzed by GCMS following microwave extraction as described above, and percent recovery was calculated.

Data analysis. Repeated measures analyses of variance were performed for propiconazole concentration and C. fagacearum isolation data using PROC MIXED in SAS version 9.1.3 (SAS Institute, Cary, NC) to accommodate covariance parameters. Incidence of $C$. fagacearum was calculated from isolation data (binary) for each tree at each distance from the injection point (percentage of samples yielding the fungus), and were arcsinetransformed for the analysis. The concentration of propiconazole in each wood sample was calculated as the mean of each of the two individual determinations because consistent repeatability of the propiconazole assay was confirmed (data not shown). Propiconazole concentration data were normally distributed, and concentrations ( $\mathrm{ppm}$ ) were not transformed for analysis. Treatment, distance from the injection point, and time since injection variables were treated as fixed effects, while tree and root effects were treated as random. The dependency of measures at all four distances within a root and at all three sampling periods was addressed using the REPEATED statement, and the covariances among repeated measures was identified as unstructured (UN). When interactions between main effects were significant, the SLICE option of PROC MIXED was used to further examine individual effects. Significant differences among means were determined by pairwise comparisons of least-squares means using the LS MEANS statement with the DIFF option $(\alpha=0.05)$.
Two roots, one from treatment 1 excavated 12 months after treatment and one from treatment 2 excavated 2 months after treatment, were dead and severely decayed at the time of sampling. Assays for propiconazole and C. fagacearum were not successful in these roots, and the samples were therefore removed from statistical analyses.

\section{RESULTS}

Propiconazole recovery from oak tissues. Under the operating conditions used for the GCMS, the retention time for propiconazole was approximately $9.65 \mathrm{~min}$. The percent recovery of propiconazole from tissue samples was positively correlated with increasing rates of the chemical in the spiked oak tissue samples. The mean recovery of propiconazole was $78,76,72,71,68,62$, and $58 \%$ for the chemical spiked levels $150,100,50,25,10,5$, and $1 \mathrm{ppm} \mu \mathrm{g} / \mathrm{g}$, respectively.

Propiconazole distribution in treated trees. Propiconazole was detected at all sampled locations in the primary roots and lower stems of trees treated prophylactically (treatment 1), therapeutically (treatment 2 ), or as part of the fungicide control treatment (treatment 3) 2, 12, and 24 months after injection. Fungicide distribution was similar for all treatments, i.e., inoculation with $C$. fagacearum did not affect propiconazole uptake and distribution in trees after injection (Table 1). Although the concentration of propiconazole in the injected solution $(\approx 3,050 \mathrm{ppm})$ was the same for all treated trees, when the concentrations of the fungicide in wood samples taken at the same time and distance from the injection point were compared, a high degree of variability in propiconazole concentration was observed among trees and even among roots of the same tree (Table 2). The highest concentration of propiconazole detected, $815.0 \mathrm{ppm}$, was in a wood sample taken from the stem $(0.33 \mathrm{~m}$ above the injection point) 2 months after treatment. The concentration of propiconazole in an adjacent stem sample from the same tree was only $458.5 \mathrm{ppm}$. In only five root samples was propiconazole not detected via the GCMS assay, all of which were sampled 24 months after treatment. Tree diameter, especially with the relationship between diameter and number of injection tees used, did not affect the concentration of propiconazole in individual samples (Table 1).

In the roots, the concentration of propiconazole decreased with increasing distance from the injection point, and was consistently higher in stem samples than in the adjacent root samples $0.33 \mathrm{~m}$ below the injection point. Two months after treatment, the average concentration of propiconazole was $64 \%$ lower in roots $0.33 \mathrm{~m}$ from the injection point than in the stem at the same distance, and $91 \%$ lower $1.0 \mathrm{~m}$ below the injection point in the roots (Fig. 1). Similar patterns of distribution were observed during other sampling periods. On average, propiconazole concentration decreased by $54 \%$ for each successive root sample, beginning in the stem $0.33 \mathrm{~m}$ above the injection point, and proceeding basipetally into the roots $1.0 \mathrm{~m}$ from the injection point. Differences in concentration with increasing distance from the injection point were observed during all sampling periods at all distances sampled $(P<0.0001)$ (Table 2).

TABLE 1. Multivariate analysis of variance for the effect of principal parameters on the concentration of propiconazole in the roots and lower stem

\begin{tabular}{lccrr}
\hline Effect & Num df & Den df & \multicolumn{1}{c}{$F$} & \multicolumn{1}{c}{$P$} \\
\hline Tree diameter & 1 & 9.8 & 0.07 & 0.7990 \\
Treatment & 2 & 5.4 & 2.50 & 0.1699 \\
Time $^{\mathrm{y}}$ & 2 & 28.2 & 16.96 & $<0.0001$ \\
Distance $^{\mathrm{z}}$ & 3 & 28.5 & 59.26 & $<0.0001$ \\
Months $\times$ distance & 6 & 30.0 & 10.64 & $<0.0001$ \\
\hline
\end{tabular}

y Time elapsed since date of treatment.

${ }^{\mathrm{z}}$ Distance from the root flare propiconazole injection site. 
Although propiconazole concentration could not be determined in the same individual roots during each of the three sampling periods because of destructive sampling techniques, the average concentration of the fungicide did decrease significantly over time in treated trees (Fig. 2). Between 2 and 24 months posttreatment, the average concentration of propiconazole in samples decreased by $72 \%$ (Fig. 2). The decrease was greatest in stem samples $(80 \%)$ and in the roots $1.0 \mathrm{~m}$ from the injection point $(81 \%)$ over the 22 month period. However, significant decreases in propiconazole concentration over time were only observed in those samples adjacent to the point of injection $(0.33 \mathrm{~m}$ above and below the injection point) over all three sampling periods (Fig. 2). In samples taken 0.66 and $1.0 \mathrm{~m}$ below the injection point, no significant decreases occurred after 12 months. Propiconazole was detected in $92 \%(n=72)$ of wood samples after 24 months. Of the five samples that did not contain propiconazole, four came from the same tree, and three of those four from the same root (i.e., propiconazole was not found in that root below the injection point).

Pathogen distribution in disease control trees. The incidence of $C$. fagacearum in disease control trees decreased with time elapsed since inoculation $(P=0.0072)$ (Fig. 3A). Two months after inoculation, $C$. fagacearum was isolated from $96 \%(\mathrm{n}=24)$ of samples from disease control trees. At that time, we were unable to isolate the pathogen from only one root or stem sample $(\mathrm{n}=24)$, which was taken $0.33 \mathrm{~m}$ below the injection point. Twelve months after injection, the pathogen was isolated from $100 \%(\mathrm{n}=18)$ of root samples but only $50 \%(\mathrm{n}=6)$ of stem samples because the pathogen was no longer found in the stem of one of the two trees sampled. After 24 months, the pathogen was isolated from only $17 \%(\mathrm{n}=24)$ of samples, and was found only in the roots. The outermost xylem increment of trees sampled 24 months after inoculation was very dry to the touch. The highest pathogen incidence observed 24 months after inoculation was $0.33 \mathrm{~m}$ below the injection point $(50 \%, \mathrm{n}=6)$, followed by $0.66 \mathrm{~m}$ below $(17 \%, \mathrm{n}=6)$. For all sampled distances, the mean pathogen incidence decreased by $82 \%$ during the 2-year study.

Pathogen distribution in treated trees. Pathogen incidence in the roots of propiconazole-treated trees (treatments 1 and 2 only) was positively correlated with distance from the injection point $(P<0.0001)$ (Fig. 3B), and the spatial and temporal distribution of the pathogen was different than that observed in disease control trees $(P<0.0001)$ (Fig. 3A). At 2 and 12 months after injection, $C$. fagacearum was found only in the roots of propiconazoletreated trees 0.66 and $1.0 \mathrm{~m}$ below the injection point. During the first 12 months, C. fagacearum was not isolated from either the root or stem sample adjacent to the injection point. However, 24 months postinjection, the pattern of pathogen distribution in propiconazole-treated trees changed. While the pathogen was again not isolated from roots $0.33 \mathrm{~m}$ below the injection point, pathogen incidence in stem samples increased to $50 \%(\mathrm{n}=12)$ and pathogen incidence at or below $0.66 \mathrm{~m}$ decreased to $17 \%(\mathrm{n}=$ 24). Pathogen incidence in stem samples was significantly greater after 24 months compared with stem samples taken 2 and 12 months after treatment. Conversely, pathogen incidence decreased in root samples 0.66 and $1.0 \mathrm{~m}$ below the injection point between 12 and 24 months posttreatment, though the difference at $0.66 \mathrm{~m}$ was not statistically significant. C. fagacearum was never isolated from root samples $0.33 \mathrm{~m}$ below the injection point in propiconazole-treated trees during this study.

Although the mean pathogen incidence was lower in samples from propiconazole-treated trees than from disease control trees

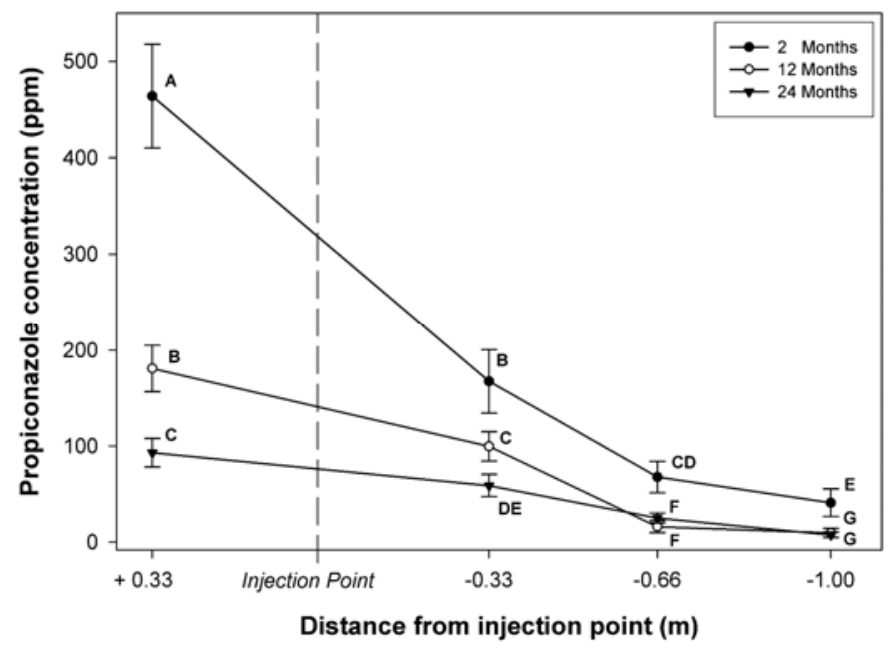

Fig. 1. Average concentration of propiconazole (ppm) in wood samples taken at different distances above (+) and below (-) the root flare injection site in trees treated with Alamo $(20.0 \mathrm{ml}$ per $2.5 \mathrm{~cm}$ diameter at $1.4 \mathrm{~m}$ height $)$ prophylactically (treatment 1), therapeutically (treatment 2), and in trees not inoculated with Ceratocystis fagacearum (treatment 3) by months after injection. Significant differences among means are indicated by different letters as determined by pairwise comparisons of least-squares means ( $\alpha=$ $0.05)$. Error bars indicate $+/-$ standard error of the mean; $n=17$ for months 2 and $12, \mathrm{n}=18$ for month 24 .

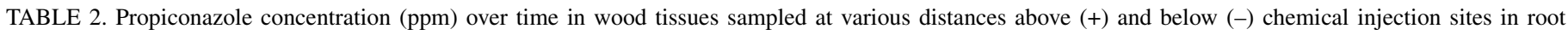
flares $^{\mathrm{y}}$

\begin{tabular}{|c|c|c|c|c|c|c|}
\hline \multirow{2}{*}{$\begin{array}{l}\text { Months } \\
\text { posttreatment }\end{array}$} & \multirow{2}{*}{$\begin{array}{c}\text { Distance from } \\
\text { injection point }(\mathrm{m})\end{array}$} & \multicolumn{5}{|c|}{ Propiconazole concentration (ppm) in samples } \\
\hline & & $\mathrm{n}$ & Mean $^{\mathrm{z}}$ & Standard deviation & Minimum & Maximum \\
\hline \multirow[t]{4}{*}{2} & +0.33 & 17 & $463.94 \mathrm{a}$ & 215.45 & 132.87 & 815.02 \\
\hline & -0.33 & 17 & $167.50 \mathrm{~b}$ & 132.53 & 30.57 & 507.89 \\
\hline & -0.66 & 17 & $67.87 \mathrm{~cd}$ & 65.02 & 1.58 & 242.85 \\
\hline & -1.00 & 17 & $41.04 \mathrm{e}$ & 57.40 & 1.21 & 189.05 \\
\hline \multirow[t]{4}{*}{12} & +0.33 & 17 & $180.80 \mathrm{~b}$ & 96.51 & 55.18 & 468.31 \\
\hline & -0.33 & 17 & $99.67 \mathrm{c}$ & 61.31 & 4.95 & 239.35 \\
\hline & -0.66 & 17 & $16.10 \mathrm{f}$ & 24.96 & 1.06 & 83.84 \\
\hline & -1.00 & 17 & $9.76 \mathrm{~g}$ & 18.93 & 0.69 & 73.74 \\
\hline \multirow[t]{5}{*}{24} & +0.33 & 18 & $93.10 \mathrm{c}$ & 61.11 & 7.47 & 254.87 \\
\hline & -0.33 & 18 & $58.89 \mathrm{de}$ & 47.68 & 0.00 & 162.63 \\
\hline & -0.66 & 18 & $25.16 \mathrm{f}$ & 21.63 & 0.00 & 70.51 \\
\hline & -1.00 & 18 & $7.66 \mathrm{~g}$ & 11.77 & 0.00 & 42.24 \\
\hline & Total & 208 & 101.54 & 149.25 & 0.00 & 815.02 \\
\hline
\end{tabular}

\footnotetext{
y Wood samples were treated with Alamo $(20.0 \mathrm{ml}$ per $2.5 \mathrm{~cm}$ diameter at $1.4 \mathrm{~m}$ height $)$ in prophylactic, therapeutic, and chemical control treatments.
}

z Significant differences among means are indicated by different letters as determined by pairwise comparisons of least-squares means $(\alpha=0.05)$. 
2 and 12 months after treatment $(P<0.0001)$, at no sampling period was a treated tree (therapeutically or preventatively treated with propiconazole) found to be completely free of the pathogen. After 24 months, there was no difference in the mean pathogen incidence in the roots and stems among disease control trees and propiconazole-treated trees $(P=0.6623)$ (Fig. 4). At no time after treatment or distance from the injection point did the incidence of C. fagacearum isolation differ between therapeutically and prophylactically treated trees. Over all three sampling periods, 53\% of inoculated roots yielded the pathogen from at least one of the three sampled distances below the injection point.

Because the pathogen was isolated so infrequently in treated trees, particularly in samples adjacent to the injection point where fungicide concentrations were highest, there was not enough data to draw statistically valid conclusions as to how fungicide concentration affected the presence of $C$. fagacearum at specific distances from the injection point at certain time intervals posttreatment. At 2 and 12 months after treatment, the concentration of propiconazole was consistently low in wood samples that yielded C. fagacearum, but concentrations varied greatly for wood tissues from which the fungus was not recovered (Fig. 5). These differences were significant at both 2 months $(P=0.00016)$ and 12 months $(P=0.009)$, but not at 24 months $(P=0.3005)$. $C$. fagacearum was not isolated from wood samples with concentrations of propiconazole higher than $36 \mathrm{ppm}$ within 12 months of treatment, but the pathogen was isolated from samples with propiconazole concentrations as high as 254 ppm 24 months after treatment. The mean and range of propiconazole concentrations in samples yielding the pathogen was $5.2 \mathrm{ppm}$ and 0.95 to $35.7 \mathrm{ppm}$, respectively, 2 and 12 months after treatment, and $64.5 \mathrm{ppm}$ and 1.4 to $254.8 \mathrm{ppm}$, respectively, after 24 months. C. fagacearum was never isolated from propiconazole control trees (treatment 3 ) during this study.

Wilt development in study trees. Oak wilt foliar symptoms were first observed in disease control trees (treatment 4) approximately 4 weeks after inoculation. Symptoms appeared in all six disease control trees within a 6-day period, and all trees were completely wilted within 8 weeks of inoculation (4 weeks after incipient wilt development) with $C$. fagacearum. Symptoms were

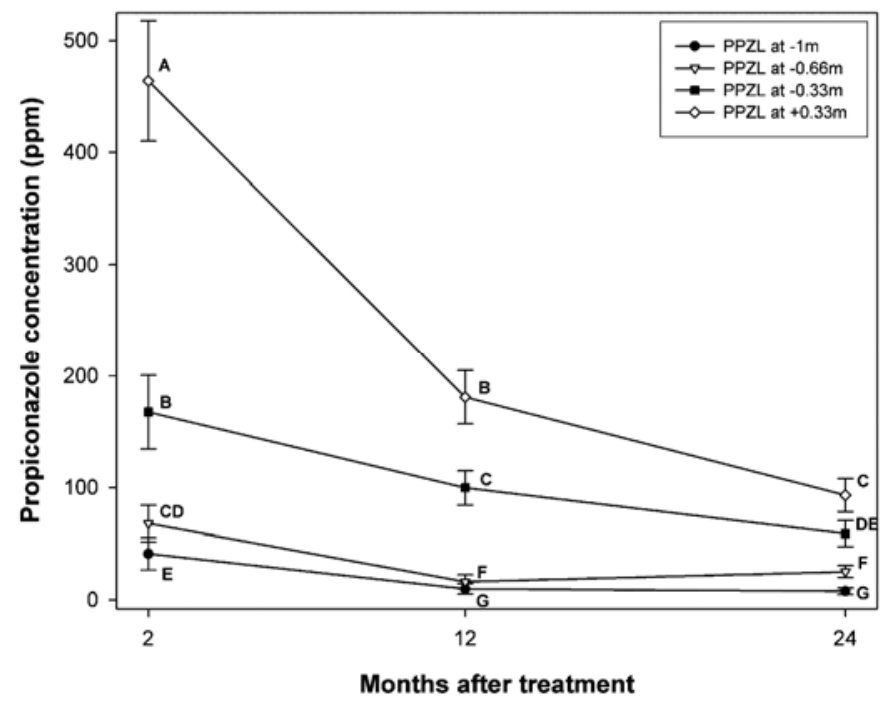

Fig. 2. Average concentration of propiconazole over time (ppm) in wood samples taken above $(+)$ and below $(-)$ the root flare injection site in trees treated with Alamo $(20.0 \mathrm{ml}$ per $2.5 \mathrm{~cm}$ diameter at $1.4 \mathrm{~m}$ height prophylactically (treatment 1), therapeutically (treatment 2), and in trees not inoculated with Ceratocystis fagacearum (treatment 3 ) by distance from the injection point. Significant differences among means are indicated by different letters as determined by pairwise comparisons of least-squares means $(\alpha=$ $0.05)$. Error bars indicate $+/-$ standard error of the mean; $n=17$ for months 2 and $12, \mathrm{n}=18$ for month 24 . observed in five of six therapeutically treated trees 8 weeks after inoculation, just prior to the initial set of root and stem sample collections. Wilt symptoms affected 25 to $50 \%$ of the crown of affected trees just prior to the onset of fall coloration, which made subsequent observations of symptom development difficult that year. Nontreated/noninoculated trees in the same forest stand did not exhibit similar wilt symptoms. Presence of $C$. fagacearum in the crowns of symptomatic trees was not confirmed by pathogen isolation at this time. However, both of the therapeutically treated trees sampled 2 months postinjection displayed these symptoms, and the pathogen was isolated from the root system of each of these trees. All symptomatic, therapeutically treated trees leafed out normally the following spring (no crown dieback), and wilt symptoms never reappeared during our 36 month observation period. In June 2007, 35 months after treatment, two prophylactically treated trees developed oak wilt and were completely wilted by July 2007. One of these trees was sampled 12 months after propiconazole treatment, the other 24 months after treatment. In the latter tree, C. fagacearum was detected in all three stem samples taken $0.33 \mathrm{~m}$ above the root collar. The pathogen was also detected in the former, but only in root samples 0.66 and $1.0 \mathrm{~m}$ below the root collar. Therefore, propiconazole prevented wilt in $100 \%(\mathrm{n}=12)$ of treated trees for the first 24 months after treatment regardless of application timing in relation to inoculation and the incidence of $C$. fagacearum in root or stem tissue, but treatment failures did begin to occur approximately 36 months
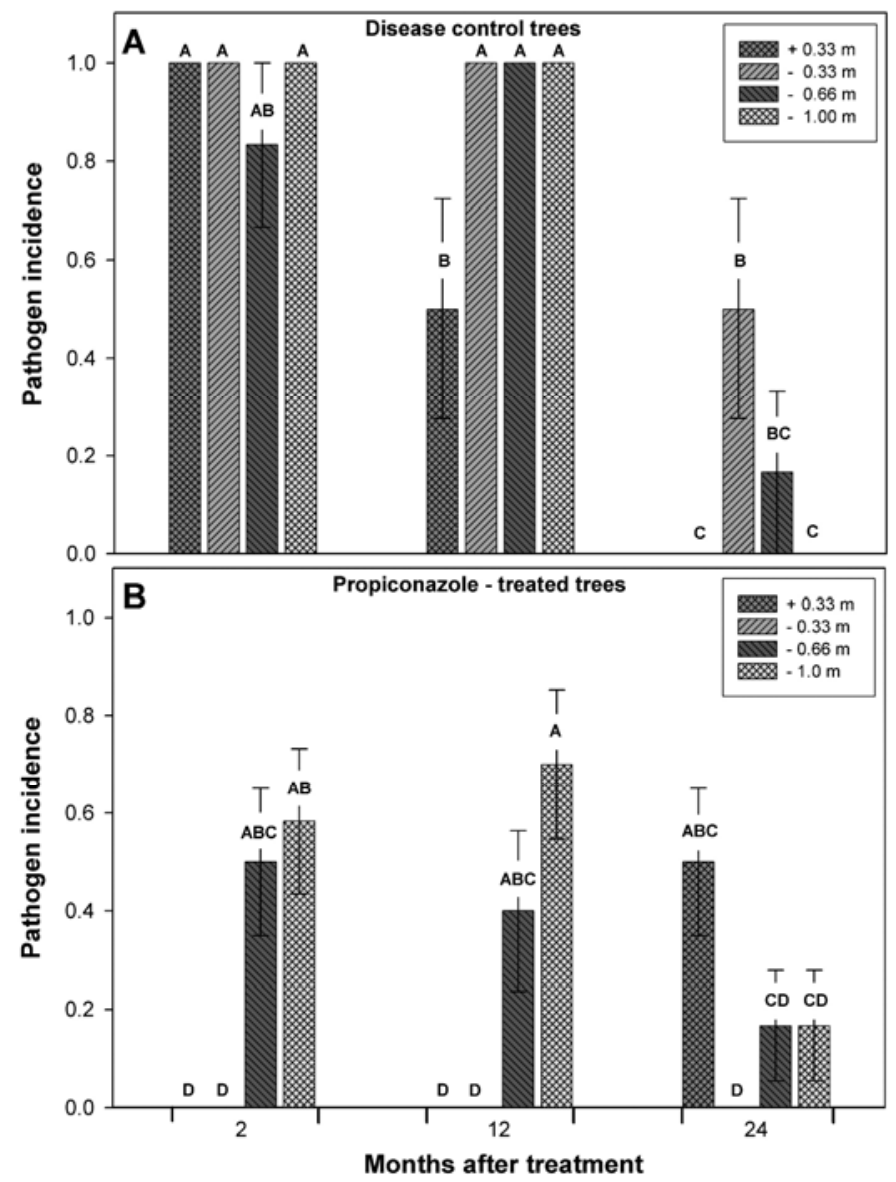

Fig. 3. Pathogen incidence in $\mathbf{A}$, disease control trees (treatment 4) and $\mathbf{B}$, propiconazole treated trees (treatments 1 and 2) by months after inoculation expressed as the proportion of wood samples taken at different distances above (+) and below (-) the root flare injection site yielding Ceratocystis fagacearum. Three roots on each tree were inoculated with a $1.0 \mathrm{ml}$ spore suspension $\left(1.0 \times 10^{6} \mathrm{spores} / \mathrm{ml}\right)$ of $C$. fagacearum $1.0 \mathrm{~m}$ from the root flare injection site. Significant differences among means are indicated by different letters as determined by pairwise comparisons of least-squares means $(\alpha=$ 0.05 ). Error bars indicate $+/-$ standard error of the mean; $n=6$. 
after treatment. None of the propiconazole control oaks (treatment 3 ) showed any symptoms of oak wilt during the course of the study.

\section{DISCUSSION}

Propiconazole distribution in treated trees. The presence of propiconazole in the primary roots of northern red oaks following macro-infusion treatment was confirmed using GCMS. Movement of propiconazole into the roots has not been previously confirmed to this extent, nor was it expected because the fungicide is believed to lack the phloem mobility necessary for significant translocation outside of the transpiration stream. Specific tissues were not assayed for propiconazole; the concentration of the fungicide was determined for the entire cross section of the sample being analyzed. Visual inspections of sample cross sections revealed blue streaking in the xylem of both stem and root samples. While the possibility of translocation in the phloem cannot be excluded, it is likely that the injected solution (which is blue in color) was mobilized in the xylem (21) or forced downward into the roots by the pressure generated from the injection system.

Propiconazole was detected $1.0 \mathrm{~m}$ from the injection point in the root systems of all treated trees (Table 2), but the concentration of propiconazole was not determined beyond this distance nor were assays conducted on roots not directly penetrated by the injection apparatus. While the total extent of propiconazole movement into the root system is therefore unknown, observed differences in concentration between samples taken $0.33 \mathrm{~m}$ below and $1.0 \mathrm{~m}$ below the injection site (Fig. 1) suggest that significant concentrations of propiconazole more than a few meters from the root collar are improbable. It is therefore unlikely that propiconazole could eradicate $C$. fagacearum from the entire root system of a mature oak. Yet, disease development did not occur for more than 24 months in propiconazole-treated trees harboring the fungus in their root system. The mechanism for propiconazole-induced disease suppression needs to be determined. One possibility is that high concentrations of the fungicide within a few meters of the root collar may limit pathogen movement into

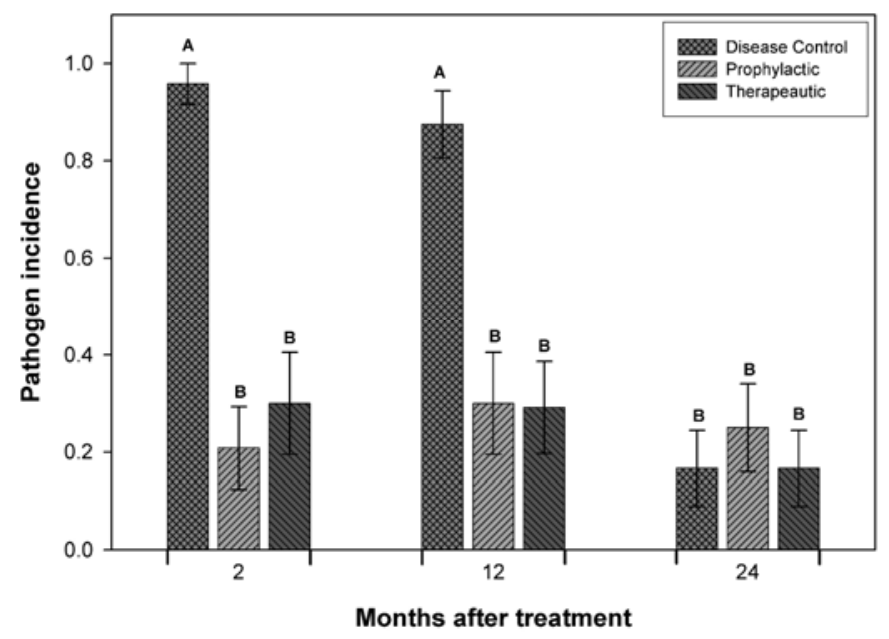

Fig. 4. Pathogen incidence in trees treated with Alamo $(20.0 \mathrm{ml}$ per $2.5 \mathrm{~cm}$ diameter at $1.4 \mathrm{~m}$ height) prophylactically (treatment 1), therapeutically (treatment 2) or in disease control trees (treatment 4) by months after inoculation expressed as the proportion of wood samples yielding Ceratocystis fagacearum for all distances from the injection site. Three roots on each tree were inoculated with a $1.0 \mathrm{ml}$ spore suspension $\left(1.0 \times 10^{6}\right.$ spores $\left./ \mathrm{ml}\right)$ of $C$. fagacearum $1.0 \mathrm{~m}$ from the root flare injection site. Significant differences among means are indicated by different letters as determined by pairwise comparisons of least-squares means $(\alpha=0.05)$. Error bars indicate $+/-$ standard error of the mean; $\mathrm{n}=21$ for month 12 prophylactic and month 2 therapeutic, $n=6$ otherwise. and subsequent colonization of above-ground tissues leading to disease development. Propiconazole may also prevent extensive colonization of the root system should a single grafted root become infected. Movement from root to root would require the pathogen to pass though the root collar zone, or through selfgrafts which tend to occur more frequently near the root collar (8).

The estimated degradation rate of propiconazole in sampled roots over the 2-year study was $69 \%$ ( $41 \%$ annually), resulting in propiconazole concentrations as high as 93.1 and $58.89 \mathrm{ppm}$ in the lower stem and primary roots, respectively, 24 months after treatment (Table 2). This is in contrast to observations of residual propiconazole levels above ground. For instance, propiconazole could not be detected in the stem and branches of American elm (6) or red oaks (S. Bernick, personal communication) 12 months after being treated with Alamo. Propiconazole degradation is proportional to temperature (6), and the presence of propiconazole in the root system and lower stem after several years may be due to lower temperatures below ground and binding of the active ingredient to the walls of xylem vessels near the injection point (12), respectively. The absence of propiconazole in the stem or branches after 1 year (15) does suggest that disease protection, especially after the first year, arises from the presence of the fungicide in the lower stem and root crown of treated trees.

Effect of propiconazole on C. fagacearum in vivo. Although the actual concentration to which the pathogen was directly exposed to in wood samples was not determined, throughout this study we were able to isolate $C$. fagacearum from samples containing propiconazole in the parts per million range well above the parts per billion ranges necessary to achieve fungicidal or fungistatic effects in vitro (22). Samples with a relatively high propiconazole concentration were very unlikely to yield $C$.

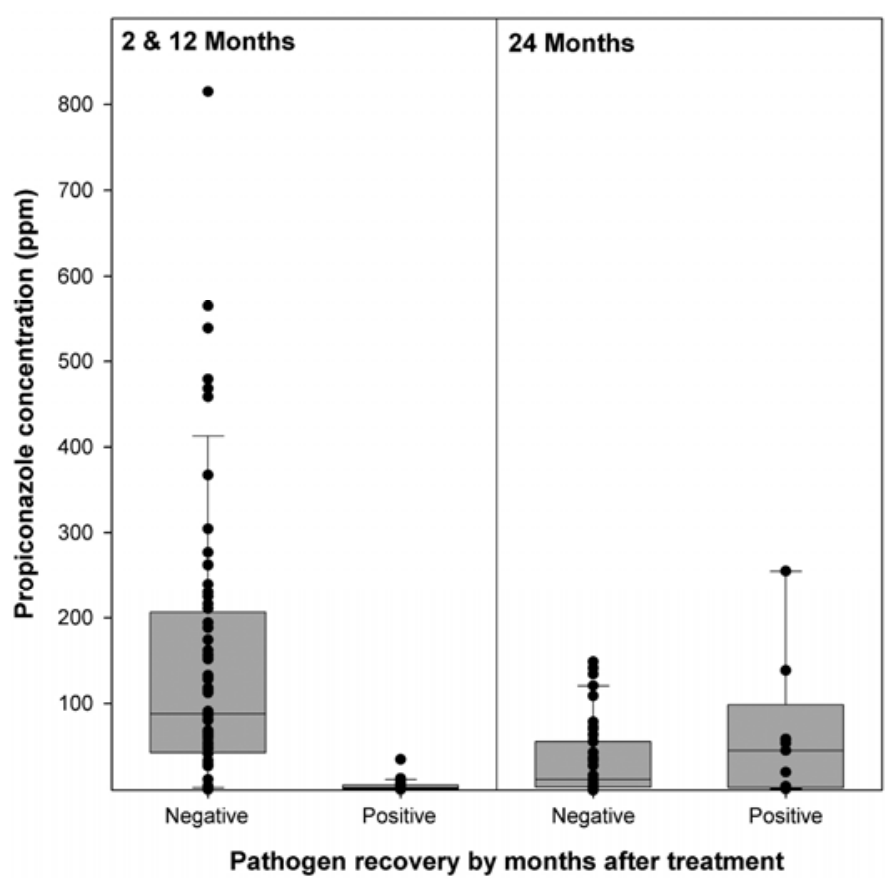

Fig. 5. Pathogen incidence 2 and 12 months or 24 months after treatment application by concentration of propiconazole ( $\mathrm{ppm})$ in wood samples taken from the stem ( $0.33 \mathrm{~m}$ above the injection site) and roots $(0.33$ to $1.0 \mathrm{~m}$ below the injection site) of trees treated with Alamo $(20.0 \mathrm{ml}$ per $2.5 \mathrm{~cm}$ diameter at $1.4 \mathrm{~m}$ height) prophylactically (treatment 1 ) or therapeutically (treatment 2 ). Three roots on each tree were inoculated with a $1.0 \mathrm{ml}$ spore suspension $(1.0 \times$ $10^{6}$ spores $/ \mathrm{ml}$ ) of Ceratocystis fagacearum $1.0 \mathrm{~m}$ from the root flare injection site. The boundary of the box closest to zero indicates the 25 th percentile, a line within the box marks the median, and the boundary of the box farthest from zero indicates the 75th percentile. Error bars above and below the box indicate the 90th and 10th percentiles. 
fagacearum 2 and 12 months after treatment, however the pathogen was isolated from samples with propiconazole in the tens to hundreds of parts per million range at 24 months (Fig. 5). The reason for the diminished effect of propiconazole on $C$. fagacearum in vivo after 1 year is unknown but may be related to lack of propiconazole mobilization into new growth from year to year, and subsequent spread of the pathogen into new growth rings. This hypothesis may be supported by the presence of $C$. fagacearum in the stems of several asymptomatic trees 24 months after treatment even though propiconazole assays indicated a high concentration of the fungicide in the surrounding wood. The noticeable absence of $C$. fagacearum $0.33 \mathrm{~m}$ below the injection site even after 24 months (Fig. 3B) may be indicative of the interconnected nature of vascular elements at the root/stem interface, which could potentially allow sufficient translocation of residual active ingredient into the new growth rings. Therefore, long-term efficacy of propiconazole may be limited by confinement to certain tissues, but residual levels of propiconazole at the root crown could extend the period of protection provided by systemic fungicide injections.

Treatment efficacy. Propiconazole applications were unable to prevent or to eradicate $C$. fagacearum from the root system of any prophylactically or therapeutically treated and C. fagacearuminoculated trees, respectively (Fig. 4). However, propiconazole treatment was able to prevent disease development for at least 24 months. Thus, inoculations of propiconazole-treated trees resulted in latent infections of the root system, suggesting that disease control in operational treatments is the result of disease suppression rather than pathogen prevention of root graft transmission. Because there was no significant difference in the incidence of $C$. fagacearum among prophylactically or therapeutically treated trees at any time during this study (Fig. 4), it may be justified to treat high-value red oaks even when root infection is suspected, so long as symptoms have yet to develop. Because propiconazole injections are used primarily to protect those trees that are at high risk of becoming infected, when managing for oak wilt, propiconazole-treated oaks should be considered to possess latent infections and be treated as potential inoculum sources. Survival of $C$. fagacearum in the root system of propiconazoletreated trees for more than 2 years and subsequent movement out of the root system into the stem indicates that retreatment every 2 years would be necessary for continued disease suppression. The long-term survival of $C$. fagacearum should be investigated in trees repeatedly treated with propiconazole on a bi-annual basis. Repeated treatments could continue to suppress disease development, but propiconazole's capacity to eradicate the pathogen with repeated injections is unknown.

Recognition of the capabilities and limitations of propiconazole applications are important to the continued, efficacious use of this control option for oak wilt and other vascular diseases such as Dutch elm disease and laurel wilt in the southeastern United States (13). Several propiconazole formulations are available and application methods vary considerably. Choice of formulation and application method based on maximum movement into and longevity in the root system may result in greater treatment efficacy for oak wilt, whereas options which achieve the greatest and most uniform distribution in the crown could be more appropriate for the management of laurel wilt and Dutch elm disease where insect vectors play a much more prevalent role in pathogen transmission.

\section{ACKNOWLEDGMENTS}

Mention of trade names does not constitute endorsement by the U.S. Department of Agriculture. This project was funded by several sources: Tree Research and Education Endowment Fund, Rainbow Treecare
Scientific Advancements, the U.S. Forest Service Pesticide Impact and Assessment Program, and the U.S. Forest Service Northern Research Station. We thank P. Castillo for excellent field support; G. Ahlstrand and A. McKnite for laboratory assistance; P. Ojiambo and C. Arellano for statistical assistance; and R. Blanchette, W. Chaney, R. Zeyen, R. Hamelin, and two anonymous colleagues for review of the manuscript. This paper is based on a portion of a Ph.D. thesis by the first author.

\section{LITERATURE CITED}

1. Amiri, A., Bussey, K. E., Riley, M. B., and Schnabel, G. 2008. Propiconazole inhibits Armillaria tabescens in vitro and translocation to peach roots following trunk infusion. Plant Dis. 92:1293-1298.

2. Appel, D. N. 1990. The use of propiconazole for control of oak wilt in live oak. Phytopathology 80:976.

3. Appel, D. N. 1991. Propiconazole for control of oak wilt. Texas Agriculture Experiment Station, Texas A\&M University, College Station.

4. Appel, D. N. 1995. The oak wilt enigma: Perspectives from the Texas epidemic. Annu. Rev. Phytopathol. 33:103-18.

5. Appel, D. N., and Kurdyla, T. 1992. Intravascular injection with propiconazole in live oak for oak wilt control. Plant Dis. 76:1121-1124.

6. Armstrong, S. D. 1999. Microwave-assisted extraction for the isolation of trace systemic fungicides from woody plant material. Ph.D. thesis. Dept. Chemistry, Virginia Polytechnic Institute and State University, Blacksburg.

7. Barnett, H. L. 1953. Isolation and identification of the oak wilt fungus. West Virginia Univ. Agric. Exp. Stn. Bull. 359T.

8. Blaedow, R. A., and Juzwik, J. 2010. Spatial and temporal distribution of Ceratocystis fagacearum in roots and root grafts of oak wilt affected red oaks. Arboric. Urban For. 36:28-34.

9. Eggers, J., Juzwik, J., Bernick, S., and Mordaunt, L. 2005. Evaluation of propiconazole operational treatments of oaks for oak wilt control. Res. Note NC-390. U.S. Dept. Agric., Forest Service, North Central Res. Stn., St. Paul, MN.

10. Gibbs, J. N., and French, D. W. 1980. The transmission of oak wilt. Res. Pap. NC-185. U.S. Dept. Agric., Forest Service, North Central For. Exp. Stn., St. Paul, MN.

11. Juzwik, J., Cook, S., Haugen, L., and Elwell, J. 2004. Oak wilt: People and trees: A community approach to management. Gen. Tech. Rep. NC240. U.S. Dept. Agric., Forest Service, North Central Res. Stn., St. Paul, MN. CD-ROM, V 1.3.

12. Lever, B. G. 1986. 'Cultar': A technical overview. Acta Hortic. 179:459466.

13. Mayfield, A. E., Barnard, E. L., Smith, J. A., Bernick, S. C., Eickwort, J. M., and Dreaden, T. J. 2008. Effect of propiconazole on laurel wilt disease development in red bay trees and on the pathogen in vitro. Arboric. Urban For. 34:317-323.

14. Nair, V. G. M. 1995. Chemotherapeutic control of oak wilt by the use of "Alamo" propiconazole. Alamo Research Symposium, Bloomington, MN.

15. Osterbauer, N. K., and D. W. French. 1992. Propiconazole as a treatment for oak wilt in Quercus rubra and Q. ellipsoidalis. J. Arboric. 18:221-226.

16. Peacock, K. L., and Fulbright, D. W. 2009. Effective longevity of propiconazole following injection into Quercus rubra. Pages 181-190 in: Proceedings of the National Oak Wilt Symposium. R. F. Billings and D. N. Appel, eds. Texas Forest Service Publication 166.

17. Pokorny, J. 1999. How to collect field samples and identify the oak wilt fungus in the laboratory. U.S. Dept. Agric., Forest Service. NA-FR-01-99.

18. Skelly, J. M., and Wood, F. A. 1974. Longevity of Ceratocystis fagacearum in ammate treated and nontreated root systems. Phytopathology 64:1483-1485

19. Struckmeyer, B. E., Kuntz, J. E., and Riker, A. J. 1958. Histology of certain oaks infected with the oak wilt fungus. Phytopathology 48:556-561.

20. Tainter, F. H., and Baker, F. A. 1996. Oak wilt. Pages 671-682 in: Principles of Forest Pathology. John Wiley and Sons, New York.

21. Tattar, T. A. 2009. Injection, infusion, and systemic movement in trees. Pages 175-180 in: Proceedings of the National Oak Wilt Symposium. R. F. Billings and D. N. Appel, eds. Texas Forest Service Publication 166.

22. Wilson, A. D., and Forse, L. B. 1997. Sensitivity of Texas strains of Ceratocystis fagacearum to triazole fungicides. Mycologia 89:468-480.

23. Wilson, A. D., and Lester, D. G. 1995. Application of propiconazole and Pseudomonas cichorii for control of oak wilt in Texas live oaks. Fungic. Nematicide Tests 50:393.

24. Young, R. A. 1949. Studies on oak wilt, caused by Chalara quercina. Phytopathology 39:425-441.

25. Yount, W. L. 1958. Results of root inoculations with the oak wilt fungus in Pennsylvania. Plant Dis. Rep. 42:548-551. 